\title{
Circulatory Arrest during Hypothermia in Cardiac Surgery: an E.E.G. Study in Children
}

\author{
ANN HARDEN,* PH.D. ; G. PAMPIGLIONE** M.D., M.R.C.P. ; D. J. WATERSTON, † M.B.E., F.R.C.S., F.R.C.S.ED
}

It is commonly believed that at normal body temperature the neurological phenomena which follow a complete circulatory arrest are full; : reversible if the blood supply to the brain is restored within three minutes. Irreversible changes in the central nervous system usually follow longer periods of circulatory arrest. However, if the body temperature is lowered the metabolic requirements of all tissues are decreased and the brain may tolerate longer periods of circulatory arrest. One of the practical applications of induced hypothermia is in open heart surgery, allowing relatively long periods of circulatory standstill for complex surgical procedures on a bloodless heart.

The electrical activity of the brain as recorded from the scalp in the electroencephalogram (E.E.G.) is closely related to metabolic activities of cerebral tissues. During open heart surgery continuous recording of the E.E.G. has been found of value to warn the surgical team of impending trouble. In addition to the routine E.E.G. monitoring, these complex operations offer the opportunity to study any alterations of brain activity that may follow a number of procedures, such as the effects of hypothermia and the changes that occur after deliberate occlusion of the whole circulation.

E.E.G. studies in man during circulatory arrest have been made with various operative techniques and mostly at " mild hypothermia" ( $33.5^{\circ}$ to $28^{\circ} \mathrm{C}$.) (Pampiglione and Waterston, 1958 ; Brechner et al., 1959 ; Pearcy and Virtue, 1959 ; ThiesPuppel and Wiemers, 1961 ; Arfel ct al., 1962). Some of these authors, however, have been more concerned with the E.E.G. changes that follow the return of circulation, rather than with the E.E.G. changes occurring immediately after the circulatory arrest. Arfel and Weiss (1962) stated that E.E.G. activity persisted for a longer period after circulatory arrest at deep hypothermia, but no systematic studies have been reported.

The present work follows a preliminary communication (Harden and Pampiglione, 1965) and concerns 23 children in whom, during open heart surgery, total circulatory arrest took place under hypothermia. The E.E.G. was recorded throughout the operative procedure, and particular attention was paid to the changes occurring immediately after complete cerebral ischaemia at various body temperatures.

\section{Material and Methods}

Before the operation the electrodes (nine silver-silver-chloride discs) were stuck on to the scalp in standard positions according to measurements from bony landmarks (Pampiglione, 1956). Contact was made with a saline jelly, and the contact resistance was lowered to less than 5,000 ohms. The electrodes were sealed with collodion. A preoperative E.E.G. was taken in all cases. During the operation the E.E.G. was continuously recorded on seven channels, while the eighth channel recorded an electrocardiogram from two further electrodes placed on the skin over the right and left deltoid region as a modified lead 1. The records were taken on an eight-channel Offner type $D$ or

* Department of Clinical Neurophysiology.

t Thoracic Unit, the Hospital for Sick Children, Great Ormond Street, London.
T ink-writing oscillograph, with an amplification of $10 \mu \mathrm{V} /$ $\mathrm{mm}$. pen deflection (often reduced), a time constant of 0.3 second, and a high-frequency response linear within $10 \%$ to $60 \mathrm{c} / \mathrm{s}$. When necessary further high-frequency cuts were employed. A paper speed of $1.5 \mathrm{~cm}$./ $\mathrm{sec}$. was used throughout.

All the patients were kept in a state of light anaesthesia by endotracheal administration of nitrous oxide and oxygen, with the addition of small doses of curare whenever necessary. When cardiopulmonary bypass was used, the administration of anaesthetic was discontinued at the onset of the extracorporeal circulation. Body temperature was recorded (by thermistor probes) from the nasopharynx and/or the oesophagus of each patient.

The present investigation was made on 23 children aged 3 to 14 years in whom the surgeons deliberately arrested the blood circulation at selected levels of hypothermia as part of the operative procedure.

Group 1.-In 15 patients mild hypothermia was induced through a veno-venous extracorporeal circuit to a body temperature between $32^{\circ}$ and $28^{\circ} \mathrm{C}$. without any bypass of the cardiopulmonary circulation. The general circulation was occluded by clamping the venae cavae. This technique allowed the surgeon a bloodless heart for procedures of short duration.

Group 2.-Eight patients on cardiopulmonary bypass were cooled by means of the heat-exchange unit in the venous-arterial extracorporeal circuit to body temperatures between $24.3^{\circ}$ and $18.5^{\circ} \mathrm{C}$. (moderate hypothermia). During cooling $\mathrm{CO}_{2}$ had been added into the oxygenator at concentrations from $2 \frac{1}{2}$ to $4 \%$. When the appropriate temperature had been reached the circulation was arrested by stopping the extracorporeal circulation. The surgeon was then able to work in a bloodless field with a still heart for fairly long periods. In these patients a temperature gradient was always noticed between oesophagus and nasopharynx. Since the oesophageal temperature was probably more closely related to the temperature of the cooled blood coming up the aorta (from the pump via the femoral artery), the nasopharyngeal temperature was thought to be a somewhat more accurate indication of intracranial temperature and was utilized in this group of patients.

\section{Results}

Group 1. Circulatory Arrest at Mild Hypothermia $\left(32^{\circ}-\right.$ $28^{\circ}$ C.).-During both induction and maintenance of cooling the E.E.G. usually showed little if any change at the light level of anaesthesia employed. The predominantly fast activities seen prior to cooling persisted at this relatively mild lowering of body temperature. The occlusion of the general circulation, by clamping the venae cavae one after the other, was followed by uniform E.E.G. changes in all cases. Initially (within 10 to 20 seconds) there was a disappearance of fast components followed by an increase in slower components. The amplitude of the slow components at first became larger and then gradually diminished, until finally there was a complete disappearance of all phasic E.E.G. activity (equipotentiality, see Fig. 1). The length of time between the first clamping of the vena cava and the final E.E.G. equipotentiality was measured. In these 15 children the average time during which phasic E.E.G. activity 
persisted was 35 seconds, with individual variations ranging between 28 and 50 seconds (see Table I).

Group 2. Circulatory Arrest at Moderate Hypothermia $\left(24.3^{\circ}-18.5^{\circ}\right.$ C. $)$.- - In this group of children, when cooling pro-

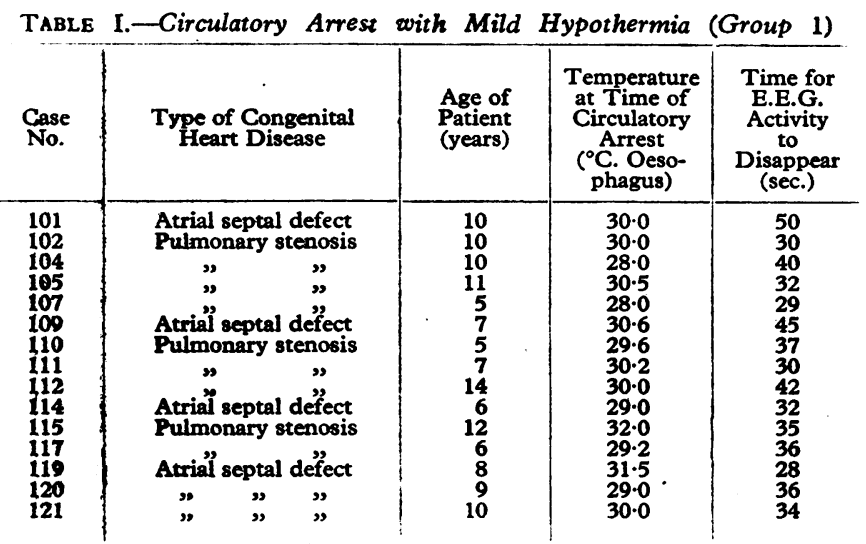

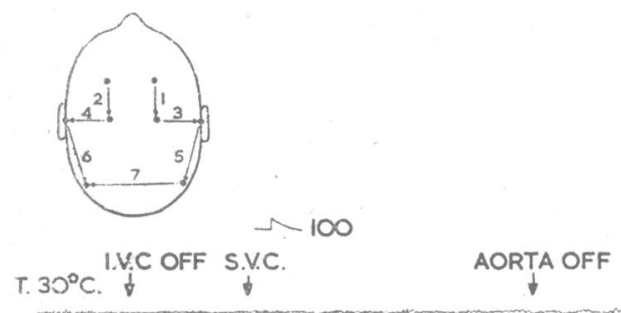

ceeded to temperatures below $28^{\circ}$ C., gradual E.E.G. changes occurred with disappearance of fast components and an increase in slow components. In six out of eight children repetitive generalized discharges appeared of the kind first described by Weiss and Arfel (1960), without, however, recognizable clinical changes. Continuous phasic activity persisted throughout, even in the patients cooled to below $20^{\circ} \mathrm{C}$. (the lowest temperature in this series was $18.5^{\circ}$ C.), the E.E.G. traces never becoming flat so long as circulation was maintained by the pump. When the circulation was arrested, by stopping the cardiopulmonary bypass, there was in the E.E.G. a gradual decrease in the amplitude of the slow wave activity with a disappearance of any discharges that might still be present, and finally there was a complete flattening of the traces to equipotentiality (see Fig. 2). The time interval between the arrest of circulation and E.E.G. equipotentiality was measured in these eight children and the average delay was 109 seconds, with individual variations between 60 and 135 seconds (see Table II). In this group the range of induced hypothermia was fairly wide.

In both groups, because of the gradual petering out of the phasic E.E.G. activity, the precise moment at which equipoten-
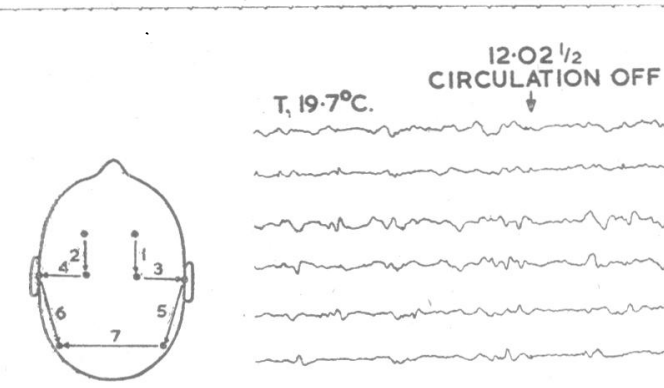

$-100$ ECG

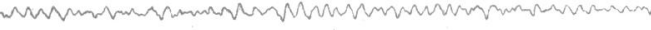

Fug. 2.-Case 47. A girl aged 13; operation on 23 May 1963 with cardiopulmonary bypass; hypothermia was induced to a nasopharyngeal temperature of $19.7^{\circ} \mathrm{C}$. (moderate hypothermia). The circulation was arrested by switching off the pump of the cardiopulmonary bypass. The amplitude of the E.E.G. activity gradually decreased and equipotentiality amplitude of the E.E.G. activity gradually decreased and equipotentiality Was reached 135 seconds (two and a quarter minutes) after the circulation
was stopped. Electrical activity from the heart still persisted as seen in was stopped. Electrical activity from the heart still
the E.C.G. trace (channel VIII). tiality occurred was sometimes a little difficult to determine. However, on repeated inspection of the same records the error involved was always less than two seconds either way.

Once equipotentiality had been reached the E.E.G. traces always remained completely flat for the whole period of circulatory arrest, irrespective of the level of hypothermia. Often, however, muscle action potentials from the temporalis were seen, for several seconds, superimposed upon the totally flat E.E.G. traces. The time intervals before complete disappearance of the phasic E.E.G. activity after the arrest of the circulation are plotted in Fig. 3 for both group 1 (mild hypothermia). and group 2 (moderate hypothermia).

TABLE II.-Circulatory Arrest with Moderate Hypothermia (Group 2)

\begin{tabular}{|c|c|c|c|c|c|}
\hline \multirow{2}{*}{$\begin{array}{l}\text { Case } \\
\text { No. }\end{array}$} & \multirow{2}{*}{$\begin{array}{l}\text { Type of Congenital } \\
\text { Heart Disease }\end{array}$} & \multirow{2}{*}{$\begin{array}{l}\text { Age of } \\
\text { Patient } \\
\text { (years) }\end{array}$} & \multicolumn{2}{|c|}{$\begin{array}{c}\text { Temperature at } \\
\text { Time of Circulatory } \\
\text { Arrest }\left({ }^{\circ} \mathrm{C} .\right) \\
\end{array}$} & \multirow{2}{*}{$\begin{array}{l}\text { Time for } \\
\text { E.E.G. } \\
\text { Activity } \\
\text { to Dis- } \\
\text { appear } \\
\text { (sec.) }\end{array}$} \\
\hline & & & $\begin{array}{c}\text { Naso- } \\
\text { pharynx }\end{array}$ & $\begin{array}{c}\text { Oeso- } \\
\text { phagus }\end{array}$ & \\
\hline 12 & $\begin{array}{l}\text { Atrial septal defect. } \begin{array}{c}\text { Anoma- } \\
\text { lous pulmonary } \\
\text { drainage }\end{array} \\
\text {... }\end{array}$ & 7 & $21 \cdot 6$ & $15 \cdot 0$ & 120 \\
\hline 15 & $\begin{array}{c}\text { Anomalous pulmonary venous } \\
\text { drainage }\end{array}$ & 14 & $19 \cdot 0$ & $17 \cdot 0$ & 120 \\
\hline $\begin{array}{l}17 \\
19\end{array}$ & 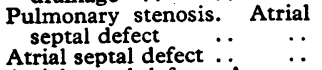 & 10 & $\begin{array}{l}24 \cdot 0 \\
23 \cdot 5\end{array}$ & $\begin{array}{l}15 \cdot 2 \\
15 \cdot 5\end{array}$ & $\begin{array}{l}105 \\
135\end{array}$ \\
\hline 23 & $\begin{array}{l}\text { Atrial septal defect. Anoma- } \\
\text { lous pulmonary venous } \\
\text { drainage }\end{array}$ & 8 & $24 \cdot 3$ & $15 \cdot 2$ & 60 \\
\hline 38 & $\begin{array}{c}\text { Anomalous pulmonary venous } \\
\text { drainage }\end{array}$ & 3 & 18.5 & 16.5 & 120 \\
\hline $\begin{array}{l}47 \\
87\end{array}$ & $\begin{array}{lll}\text { Cor triatriatum } & \ldots & \ldots \\
\text { Fallot's tetralogy } & \ldots & \end{array}$ & $\begin{array}{r}13 \\
8\end{array}$ & $\begin{array}{l}19 \cdot 7 \\
22 \cdot 1\end{array}$ & $\begin{array}{l}16 \cdot 8 \\
22 \cdot 0\end{array}$ & $\begin{array}{r}135 \\
75\end{array}$ \\
\hline
\end{tabular}


The arrest of the cerebral circulation must have occurred rather more abruptly in the cases of group 2 (by switching off the bypass) than in group 1, when the occlusion of the venous return to the heart was achieved by clamping the venae cavae. Moreover, the superior and inferior venae cavae were not occluded simultaneously, the interval varying between a minimum of five and a maximum of 35 seconds (usually the superior vena cava was the first to be occluded). In our calculations the delay to E.E.G. equipotentiality was measured from the time the first vessel was occluded. If the occlusion of the two venae cavae had been simultaneous the delay to E.E.G. equipotentiality in group 1 would have been even shorter, and the difference between group 1 and group 2 even greater.

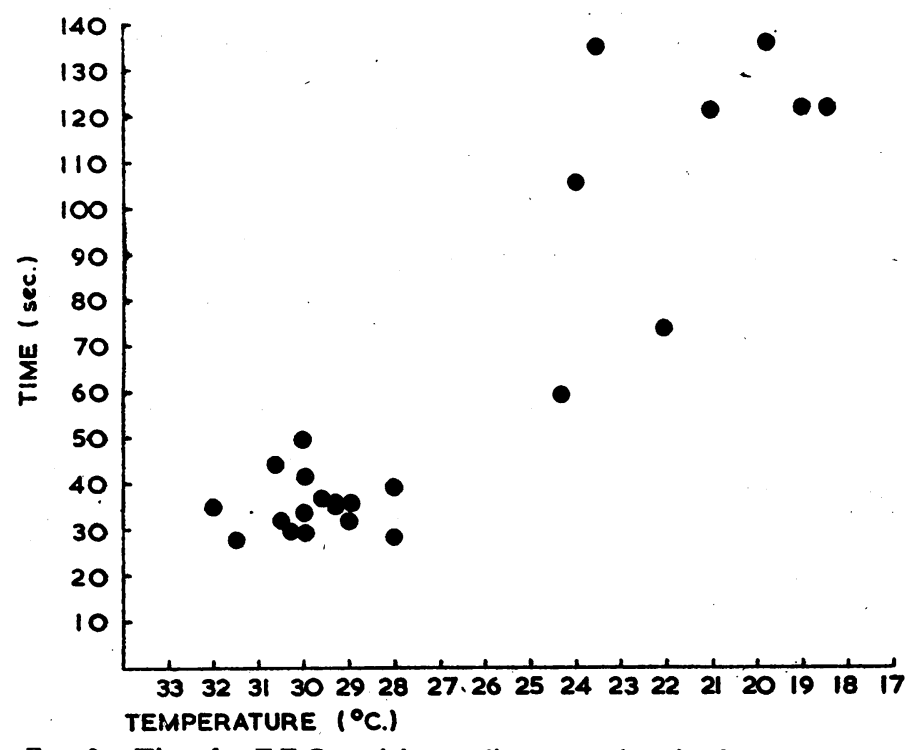

FIG. 3.-Time for E.E.G. activity to disappear with circulatory arrest at various temperatures.

\section{Discussion}

From our observations the duration. of persistence of phasic E.E.G. activity was much longer when circulatory arrest occurred at $24.5^{\circ}$ to $18.5^{\circ} \mathrm{C}$. than at $32^{\circ}$ to $28^{\circ} \mathrm{C}$. From the work of Arfel and Weiss (1962) and Piot et al. (1962) it appears that the E.E.G. activity may persist even longer (two to four minutes) when circulatory arrest is carried out at still lower levels of hypothermia $\left(10-15^{\circ} \mathrm{C}\right.$.).

In animals the effect upon the E.E.G. of an abrupt arrest of cerebral circulation at normothermia has been studied by various authors (Simpson and Derbyshire, 1934 ; ten Cate and Horsten, 1952 ; Hirsh et al., 1957, all in cats ; and Brechner et al., 1961, in the dog), the phasic E.E.G. activity disappearing within 20 to 30 seconds. In these experiments circulatory arrest was usually achieved by sudden occlusion of the arterial blood supply to the brain. Such a technique would be expected to produce a much more rapid cerebral ischaemia than that obtained by occlusion of the venae cavae.

Data on deliberate surgical circulatory arrest in man at normothermia are not available. If we compare studies on animals at normothermia with our studies on humans at mild hypothermia, and if allowance is made for variations in surgical techniques, the delay to E.E.G. equipotentiality after circulatory arrest at normothermia and at mildly hypothermic levels may not be substantially different. Mild hypothermia had little if any effect on the E.E.G. patterns of light anaesthesia in our patients, and this suggests that the cerebral metabolism underlying electrogenesis is probably not grossly altered by such mild hypothermia. Merlis (1958) stated, however, that while the time for the E.E.G. to disappear after arrest of the circulation both at $26-28^{\circ} \mathrm{C}$. and at normothermia was of the same magnitude, the brain withstands much longer periods of ischaemia at mild hypothermia than at normothermia.

In the absence of any substantiating evidence it might be argued equally well that the protective effect of hypothermia against cerebral ischaemia at such mildly lowered body temperatures was only minimal and that other factors might be relevant. For example, although it is generally accepted that at normal body temperature a circulatory arrest lasting more than three to four minutes results in varying degrees of cerebral damage, Hirsch et al. (1957) demonstrated in the cat and in the rabbit that asphyxia of the heart may be one of the most important limiting factors to successful resuscitation. They found that the brain could be revived without damage even after 8 to 10 minutes of complete selective cerebral ischaemia at normothermia provided that an efficient circulation was available to perfuse the brain immediately after the period of arrest. An inadequate cardiac output due to the myocardial ischaemia may give rise to a further period of inadequate cerebral perfusion, and represent the "last straw" responsible for the final cerebral damage. This view, at variance with some accepted concepts, is worth further experimental studies, supplemented by any well-documented accidental observation in man.

In our observations the range of individual variations within both group 1 and group 2 was considerable, but this may have been due to a number of complicating factors in addition to the hypothermia. For instance, the blood-pressure at the time of the arrest must be an important factor, as suggested by ThiesPuppel and Wiemers (1961), and also from earlier animal experiments by Gänshirt and Zylka (1952). Any period of embarrassed cerebral circulation withoút complete recovery prior to a circulatory arrest would certainly complicate the evaluation of results, but in our present series no known circulatory complications had occurred.

Another complicating factor may have been due to temperature gradients between the site of temperature measurements and the brain. This has been shown to occur during cooling in animals (Shields and Lewis, 1959). The occurrence of temperature gradients between various parts of the brain itself during cooling has been suggested by the animal studies of Zingg and Kantor (1960), and the rate of cooling may represent yet another variable.

The evaluation of results might be influenced by the patient's age. In our observations the age of each child was plotted against the delay to E.E.G. equipotentiality after circulatory arrest, irrespective of the level of hypothermia (Fig. 4). In group 1 the ages varied from 5 to 14 years, and there was no

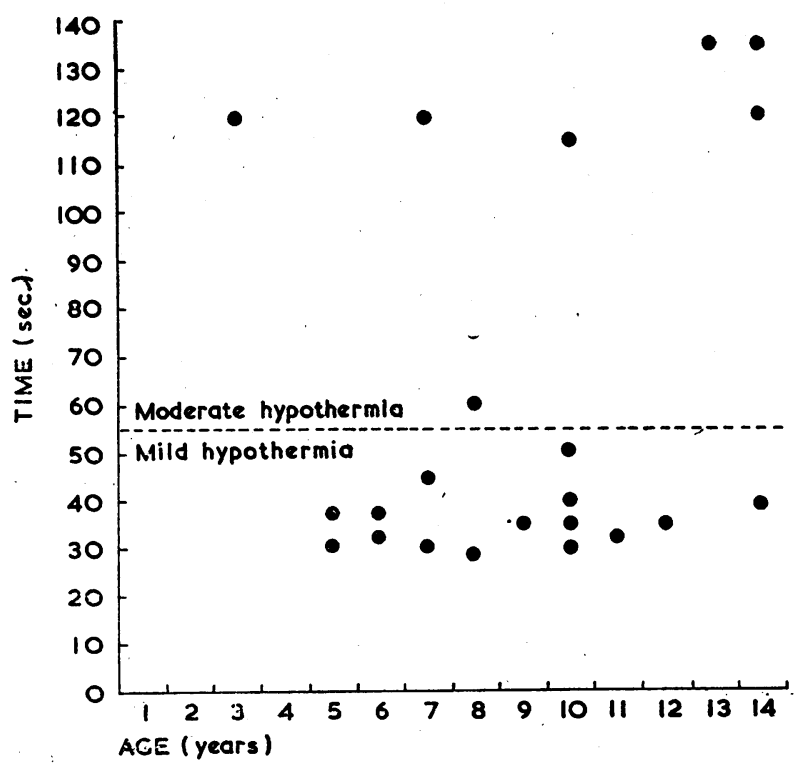

FIG. 4.-Time for E.E.G. activity to disappear with circulatory arrest during hypothermia in relation to age. 
obvious difference in delay between the younger and the older children in spite of the considerable individual variations. The number of subjects is small in group 2 ; however, three children of widely varying ages $(3,7$, and 14 years) showed a practically identical delay of about 120 seconds at comparable levels of hypothermia. We may conclude that in our material, at least in relation to the age groups considered, there was no evidence that a younger child, after circulatory arrest, might show a longer persistence of E.E.G. activity than an older one. It would be interesting to know whether the central nervous system of young babies might behave differently from that of the age group considered in the present paper, as suggested by the work of Jilek et al. (1964) on rats during early development.

The detailed shape of any curve to be drawn from Fig. 3 could not be established under the experimental situation offered (all our children suffered from heart defects of varying severity), as the complicating factors were many and the number of patients was rather small. With a decrease in body temperature between $32^{\circ}$ and $18.5^{\circ}$ C. the delay to E.E.G. equipotentiality, rather than bearing a linear relationship, may follow an exponential curve, as suggested by comparable animal studies of Gänshirt et al. (1954). The protective effect of cooling, therefore, could be proportionally much greater at moderate and deep hypothermia than at mild hypothermia.

The increased time lag for the disappearance of E.E.G. activity with lower body temperatures is probably related to a decreased rate of utilization of metabolites from the stagnating blood after the circulatory arrest. Thorn et al. (1958) have measured the concentration of metabolites in the brain of rabbits after various periods of complete ischaemia at both $37^{\circ}$ and $26^{\circ} \mathrm{C}$. At the lower temperature glycolysis proceeded more slowly and phosphocreatine and adenosine triphosphate remained in detectable amounts for at least two to three times longer than at normal body temperature.

The measurement of the delay to E.E.G. equipotentiality after deliberate circulatory arrest may represent an indication of the availability of metabolites to the brain at the time of the circulatory standstill. In future work it would be of interest to find out whether the delay to E.E.G. equipotentiality after circulatory occlusion might offer a prospective measure of the length of time during which total cerebral ischaemia can be safely tolerated by the brain at various temperatures.

\section{Summary}

During the course of open heart surgery a deliberate arrest of the circulation at lowered body temperature was performed as part of the routine surgical procedure. In 23 children B.E.G. studies were carried out throughout the operation and particular attention was paid to the changes occurring immediately after complete cerebral ischaemia at various body tem- peratures. Mild hypothermia $\left(32-28^{\circ}\right.$ C.) had been induced in 15 cases (group 1 ) and moderate hypothermia $\left(24.3-18.5^{\circ} \mathrm{C}\right.$.) in a further eight cases (group 2).

In each case the occlusion of the circulation was followed by E.E.G. changes and finally by complete disappearance of all phasic activity. The time interval between circulatory arrest and E.E.G. equipotentiality was much greater in the children of group 2 with moderate hypothermia (average time 109 seconds) than in those of group 1 with mild hypothermia (average time 35 seconds).

The length of time between circulatory occlusion and the flattening of the E.E.G. traces probably represents a measure of the rate of cerebral utilization of available metabolites from the stagnating blood. Within the age group studied ( 3 to 14 years) there was no evidence that total cerebral ischaemia, at comparable temperatures, could have a different effect on the brain of the younger than of the older children.

It is a pleasure to thank all the medical, nursing, and technical staff whose co-operation in the operating-theatre has made this study possible. The support of the Joint Research Board of the Hospital for Sick Children is gratefully acknowledged.

\section{REFERENCES}

Arfel, G., Du Bouchet, N., and D'Allaines, F. (1962). Actualités cardiol. angéiol. int., 11, 269.

_ and Weiss, J. (1962). Ann. Chir. thorac. cardiov., 1, 666.

Brechner, V. L., Bethune, R. W. M., Kavan, E. M., Bauer, R. O., Phillips, R. E., and Dillon, J. B. (1961). Anesth. Analg. Curr. Res. 40, 1 .

- Kavan, E. M., Bethune, R. W., Bauer, R. O., and Dillon, J. B. (1959). Amer. Surg., 25, 833.

Gänshirt, $H$, Hirsch, $H$, Krenkel, W., Schneider, M., and Zylka, $\mathbf{W}$ (1954). Arch. exp. Path. Pharmak., 222, 431.

— and Zylka, W. (1952). Pfiügers Arch. ges. Physiol., 256, 181.

Harden, A., and Pampiglione, G. (1965). F. Physiol. (Lond.), 181, 49P.

Hirsch, H., Euler, K. H., and Schneider, M. (1957). Pflïgers Arch. ges. Physiol., 265, 281.

Jlek, L., Fischer, J., Krulich, L., and Trojan, S. (1964). Progress in Brain Research, Vol. 9, The Developing Brain, edited by W. A Himwich and H. E. Himwich. Elsevier, Amsterdam.

Merlis, J. K. (1958). Electroenceph. clin. Neurophysiol., 10, 179.

Pampiglione, G. (1956). Proc. electrophysiol. Technol. Ass., 7, 80.

- and Waterston, D. J. (1958). Electroenceph. clin. Neurophysiol. $10,354$.

Pearcy, W. C., and Virtue, R. W. (1959). Anesthesiology, 20, 341.

Piot, C., Colomb, G., Lhermitte, F., and Mathey, J. (1962). Ann. Chir. thorac. cardiov., 1, 681 .

Shields, T. W., and Lewis, F. J. (1959). Surgery, 46, 164.

Simpson, H. N., and Derbyshire, A. J. (1934). Amer. F. Physiol., 109, 99.

ten Cate, J., and Horsten, G. P. M. (1952). Arch. int. Physiol., 60, 441

Thies-Puppel, H., and Wiemers, K. (1961). In Cerebral Anoxia and the Electroencephalogram, edited by J. S. Meyer and H. Gastaut, ch. 28 . Thomas, Springfield, Illinois.

Thorn, W., Scholl, H., Pfleiderer, G., and Mueldener, B. (1958). $f$ Neurochem., 2, 150

Weiss, J., and Arfel, G. (1960). Rev. neurol., 103, 22.

Zingg, W., and Kantor, S. (1960). Surg. Forum, 11, 192. 